GEOLOGY

\section{Phases of the Manile}

\section{from a Correspondent}

A SYMPOSIUM on phase transformations and the Earth's interior, sponsored by the International Upper Mantle Committee and the Australian Academy of Science, was held in Canberra from January 6 to 11 . The sixty-five papers presented results from the wide range of disciplines and techniques which have been applied to the investigation of the Earth's mantle.

In sessions devoted to crystallographic studies, Drs N. Morimoto and P. B. Moore presented parallel studies solving the modified spinel structures produced experimentally at high pressures in some $\mathrm{M}_{2} \mathrm{GeO}_{4}$ and $\mathrm{M}_{2} \mathrm{SiO}_{4}$ compounds. The structures are orthorhombic but with oxygen atoms approximately in cubic close packing as in the spinel structure. Olivine $\left(\mathrm{Mg}_{2} \mathrm{SiO}_{4}\right)$ transforms to this structure at high pressure and the structure is of great importance in understanding the crystal chemistry of the Earth's mantle.

Syntheses of seismic data have led D. L. Anderson to propose very specific models with rapid changes in seismic velocity over small depth intervals between 300 and $1,000 \mathrm{~km}$ deep in the transition zone of the upper mantle. These were interpreted in terms of solid-solid phase changes in the major silicates, changes in composition and, in the upper $200 \mathrm{~km}$ of the mantle, partial melting. F. Press described models of density distribution in the upper mantle based on Monte Carlo methods of data reduction which required higher densities in the uppermost $100 \mathrm{~km}$ than those inferred in most recent mantle models. G. Woollard's analysis of gravity data, however, favours the retention of the commonly accepted figure of $P=3 \cdot 3-3 \cdot 4$.

The integration of seismic studies, defining regions of rapid increase in seismic velocity in the Transition Zone (region C), with experimental high pressure studies of phase changes in olivines, pyroxenes, garnets and other silicates, was an important feature of the conference. A. E. Ringwood, S. Akimoto and N. Kawai presented experimental data on the olivine $\rightarrow$ spinel and olivine $\rightarrow$ "modified" spinel transformations, pyroxenes $\rightarrow$ garnet, ilmenite or spinel + stishovite transformations, and feldspar $\rightarrow$ hollandite structure. R. A. Binns reported the discovery of a natural spinel polymorph of olivine in a shocked meteorite. The transformations of olivine and pyroxenes to denser structures were considered to account for the velocity increases in the $250-400 \mathrm{~km}$ depth interval, and Ringwood gave experimental evidence concerning silicate analogues which supports the interpretation that rapid velocity inereases at a depth of $600-700 \mathrm{~km}$ are due to breakdown of spinel and garnet structures to denser phases. It was suggested that $\mathrm{Mg}_{2} \mathrm{SiO}_{4}$ transforms to a structure related to that of strontium plumbate or to a mixture of $\mathrm{MgSiO}_{3}$ (ilmenite structure) $+\mathrm{MgO}$. The Ca-rich garnets probably transform to a perovskite-like structure, while Mg-rich garnets probably transform to the ilmenite structure.

Knowledge of solid-liquid equilibria in upper mantle conditions is required for an adequate understanding of the origin of magmas within the upper mantle. Several papers dealt with melting relations in simple and natural rock systems in the presence of an aqueous vapour phase at high pressures. The potential role of very small quantities of water in the upper mantle received much attention, and several speakers attributed the presence of the low velocity zone in the upper mantle to the presence of small quantities of water-bearing silicate liquids at temperatures well below the dry solidus.

Several sessions were devoted to examples of natural processes, sampling the lower crust and upper mantle. N. V. Sobolev summarized the extensive data on xenoliths of mantle origin in the Siberian diamond pipes and also on the deep crustal, eclogitic metamorphic terrains of the USSR.

M. J. O'Hara used the results of published experimental studies on basalts and peridotites to suggest that only garnet lherzolite xenoliths in kimberlite were possible primary mantle compositions capable of acting as source rocks for basaltic magma extraction.

\section{THIN FILMS}

\section{Electrical Conductivity Measured}

\section{from our Solid State Physics Correspondent}

WHeN thin metal films become so thin that they require a stretch of the imagination as well as of the material, the chief mechanism for passing an electric current can, in certain conditions, be a quantum mechanical tunnelling of electrons between different areas of the film. This was the upshot of a lecture delivered at the Royal Society last week by Dr J. M. Hill of the Electrical Research Association at Leatherhead, in which he attempted to explain some of his measurements of electrical conductivity in extremely thin metal films.

The films were prepared by evaporating the metal on to the surface of a suitably smooth dielectric, such as soda glass or alumina borosilicate glass. The resulting metal layer has a texture like very closely spaced drops of liquid, the size and separation of the globules being determined by the rate of deposition of the metal. Dr Hill has carried out conductivity measurements on specimens with globules of various sizes and separations, and has found that the conduction process always takes place through the glass substrate supporting the film.

He analysed the measurements in terms of two possible conduction processes, quantum mechanical tunnelling and thermal activation of the electrons. Four categories of film were found to occur, according to whether the diameter and separation of the globules exceeded 200 ängströms and 40 ängströms respectively. For large globules and small separation the tunnelling process dominates and for small globules and large separation the thermal activation process dominates.

After a half-hearted apology for still thinking in ängströms rather than SI units-more subtle excuses for retaining the ängström will no doubt be found as time goes on-Dr Hill went on to compare theoretical estimates of the heights of the potential barriers between globules with those deduced from his experiments. Some measure of agreement was obtained except for small globules, but refinements to the theory are needed before the conduction mechanism in ultrathin films can be considered as quantitatively understood. 